\title{
End-Tidal Partial Pressure of Carbon Dioxide and Acute Mountain Sickness in the First 24 Hours Upon Ascent to Cusco Peru (3326 meters)
}

\author{
Danielle J. Douglas, MD; Robert B. Schoene, MD \\ From the Department of Emergency Medicine, University of California, San Diego Medical Center, Naval Medical Center, San Diego, CA \\ (Dr Douglas); and the Division of Pulmonary and Critical Care Medicine, Department of Medicine, University of Washington School of \\ Medicine, Seattle, WA and Bozeman Deaconess Hospital, Bozeman, MT (Dr Schoene).
}

\begin{abstract}
Objective.-To explore the association of end-title partial pressure $\left(\mathrm{PetCO}_{2}\right)$ and oxygen saturation $\left(\mathrm{SpO}_{2}\right)$ with the development of AMS in travelers rapidly ascending to Cusco, Peru $(3326 \mathrm{~m})$.

Methods.-Using the 715 TIDAL WAVE Sp handheld, portable capnometer/oximeter, we measured $\mathrm{SpO}_{2}$ and $\mathrm{PetCO}_{2}$ in 175 subjects upon ascent to Cusco, Peru (3326 m) from Lima (sea level) (a mean time of 3.9 hours.) Symptoms of AMS were recorded at the same initial time on arrival to altitude and 24 hours later using the Environmental Symptoms Questionnaire (ESQ).

Results.-This study showed that no subjects with the lowest $\mathrm{PetCO}_{2}$ of 23 to $30 \mathrm{~mm} \mathrm{Hg}$ had AMS $(P<.044)$. The data also demonstrate that subjects with a higher $\mathrm{PetCO}_{2}(36-40 \mathrm{~mm} \mathrm{Hg})$ and lower $\mathrm{SaO}_{2}(72 \%-86 \%)$ have a higher incidence of AMS.

Conclusion.-The most important finding of this study is that $\mathrm{PetCO}_{2}$ upon ascent was found to have a more significant effect than $\mathrm{SpO}_{2}$ on a subject's ultimate ESQ score. This study demonstrates that those individuals with a brisk ventilatory response upon ascent to moderate altitude, as measured by $\mathrm{PetCO}_{2}$, did not develop AMS, whereas a blunted ventilatory response, as reflected in the highest PetCO was related to the subsequent development of AMS.
\end{abstract}

Key words: high altitude, acute mountain sickness, carbon dioxide, oxygen saturation, ventilation, hypoxemia, Cusco, Peru

\section{Introduction}

The pathophysiology of acute mountain sickness (AMS) has been extensively researched and debated in the literature. Lower oxygen saturations $\left(\mathrm{SpO}_{2}\right)$ have been associated with the development of acute mountain sickness in sojourners to high altitude. Lower $\mathrm{SpO}_{2}$ values could be secondary to a more blunted ventilatory response than normal upon ascent and/or impaired gas exchange in the lung. We wanted to evaluate the ventilatory response upon ascent to high altitude and, thus, hypothesized that those individuals with the lowest initial partial pressure of end-tidal $\mathrm{PCO}_{2}\left(\mathrm{Petco}_{2}, \mathrm{~mm} \mathrm{Hg}\right)$, as a measure of a higher alveolar ventilation, and highest

Corresponding author: Danielle J. Douglas, MD, University of California San Diego, 3368 Governor Drive, Box F325, San Diego, CA 92122 (e-mail: danielle_d@yahoo.com). percutaneous oxygen saturation $\left(\mathrm{SpO}_{2}, \%\right)$ would have the lowest incidence of AMS.

\section{Background}

Cusco, Peru (3326 m) is a mountain town in the Andes often used by trekkers from the lowlands prior to commencing their trek along the Inca Trail. Acute mountain sickness (AMS) is commonly seen in this small Peruvian town; however, there have been no studies to characterize the incidence of AMS in these sojourners. This is the first study evaluating the incidence of AMS at Cusco.

AMS is commonly seen in healthy individuals who ascend too rapidly to high altitude. ${ }^{1}$ Symptoms of AMS are characterized by headache, nausea, vomiting, anorexia, lack of energy, and disturbed sleep. These symptoms can be felt as early as 8 to 24 hours 
Table 1. Demographic data and incidence of acute mountain sickness (AMS) on day $2^{a}$

\begin{tabular}{|c|c|c|c|c|c|c|c|c|c|}
\hline \multirow[b]{2}{*}{ Variables } & \multirow{2}{*}{$\begin{array}{l}\text { No } \\
\text { response }\end{array}$} & \multicolumn{2}{|c|}{$\begin{array}{c}\text { Participants } \\
(n=172)\end{array}$} & \multicolumn{2}{|c|}{$\begin{array}{c}\text { No AMS } \\
(n=115)\end{array}$} & \multicolumn{2}{|c|}{$\begin{array}{c}A M S \\
(n=57)\end{array}$} & \multirow{2}{*}{$\begin{array}{c}\text { Combined }^{b} \\
\text { no. }\end{array}$} & \multirow[b]{2}{*}{$P$ value } \\
\hline & & no. & $\%$ of total & no. & $\%$ of total & no. & $\%$ of total & & \\
\hline Male gender & & 85 & 49.70 & 55 & 48.10 & 30 & 53.10 & 172 & .61 \\
\hline Female gender & 0 & 87 & 50.30 & 60 & 51.90 & 27 & 46.90 & & .61 \\
\hline Mean age (yr) & 2 & 40.6 & 15.90 & 40.4 & 15.70 & 42.1 & 16.70 & 161 & .73 \\
\hline \multicolumn{10}{|l|}{ Smoker } \\
\hline Yes & & 22 & 12.70 & 15 & 13.00 & 7 & 12.28 & 152 & .55 \\
\hline No & 20 & 130 & 75.58 & 100 & 87.00 & 30 & 52.63 & & .55 \\
\hline \multicolumn{10}{|c|}{ Acetazolamide Use } \\
\hline Yes & & 30 & 20.10 & 24 & 21.10 & 6 & 10.52 & 146 & .27 \\
\hline No & 26 & 116 & 79.90 & 90 & 78.90 & 26 & 45.61 & & .27 \\
\hline
\end{tabular}

${ }^{a}$ AMS is based on ESQ score $\geq 0.7$.

${ }^{b}$ Combined value is the total when both the variable measured (ie, Acetazolamide) and AMS are not missing.

after arrival at altitude $(2000 \mathrm{~m})$ but are usually most pronounced at 48 hours and 72 hours. The prevalence of AMS has been as high as $43 \%$ in trekkers reaching Pheriche, Nepal $(4343 \mathrm{~m})^{2}$ and about $22 \%$ in visitors to the resort area of Summit County, CO $(3000 \mathrm{~m}) .^{3}$

Within 4 hours of their arrival to Cusco (day 1, $3326 \mathrm{~m}$ ), subjects were asked to provide informed consent for the study, partial pressure of end-tidal $\mathrm{PCO}_{2}$ $\left(\mathrm{PetCO}_{2}, \mathrm{~mm} \mathrm{Hg}\right)$ and oxygen saturation $\left(\mathrm{SpO}_{2}, \%\right)$ measured, and the Environmental Symptoms Questionnaire (ESQ) administered. ${ }^{4}$ Subsequent development of AMS was measured by the ESQ 24 hours later (day 2) at altitude. We hypothesized that those people with the lowest $\mathrm{PetCO}_{2}$, as a measure of alveolar ventilation, and higher $\mathrm{SpO}_{2}$ would have a lower incidence of AMS.

\section{Methods}

\section{SUBJECTS}

This study enrolled 246 subjects from May 1 to May 30, 2006, in Cusco, Peru. Subjects were selected randomly. Upon arrival to the center square of Cusco, tourists were approached by 1 of 3 research assistants and asked to participate in the study. Subjects were excluded from the study if they could not speak English or Spanish or establish verbal or written comprehension of the study. Age less than 18 years, signs or symptoms of acute infection, or sleeping above 3326 meters within the previous 6 months also were exclusion criteria. Subjects with known chronic disease that could cause them to be more susceptible to altitude illness ${ }^{3}$ were excluded from participating in the study. These conditions included a cardiac history of congestive heart failure or myocardial infarction within the previous 2 years; pulmonary history for recurrent pneumonia or pulmonary fibrosis; obesity; hematologic disorders such as thalassemia, sickle cell disease/trait, or anemia; renal disease; and neurologic diseases, such as stroke or aneurysm. Subjects who smoked and those who took acetazolamide were included in the main cohort but were also analyzed in a subset analysis. Demographic data for the subjects and the corresponding incidence of AMS are given in Table 1.

Consent for human research was approved by the Institutional Review Boards of the University of California San Diego Health Center Human Research Protections Program and Comite Institucional de Etica (CIE) of the Universidad Peruana Cayetano Heredia.

\section{PROTOCOL}

The Novametrix $\mathrm{CO}_{2}$ detector was calibrated using an internal calibrating system prior to use on each patient. After giving informed consent, within the first 4 hours upon arrival to Cusco (day 1), $\mathrm{Petco}_{2}(\mathrm{~mm} \mathrm{Hg})$ and $\mathrm{Spo}_{2}$ (\%) were measured, and the ESQ administered to the subjects. On day 2, trekkers completed another ESQ. This method allowed us to investigate the association of initial values of $\mathrm{Petco}_{2}$ and $\mathrm{Spo}_{2}$ levels with the later development of AMS.

\section{DATA COLLECTION}

Two handheld portable spirometers (Novametrix Medical Systems Inc, Wallingford, CT) were used for the measurements. These devices have been approved by the US Food and Drug Administration for the evaluation of pulse oximetry and $\mathrm{PetCO}_{2}$ measurements in clinical settings both in medical centers and in the field setting. An 
Table 2. Initial $\mathrm{PetCO}_{2}$ level and its correlation to Day 2 acute mountain sickness (AMS) ${ }^{a}$

\begin{tabular}{cccccc}
\hline Initial PetCO 2 level & $23.7-30.0$ & $31.0-35.0$ & $36.0-40.0$ & $41.0-52.3$ & Combined \\
\hline AMS & $\mathrm{n}=7$ & $\mathrm{n}=59$ & $\mathrm{n}=69$ & $\mathrm{n}=37$ & $\mathrm{n}=172$ \\
Yes & $0(0 \%)^{b}$ & $29 \%(17)$ & $39 \%(27)$ & $35 \%(13)$ & $33 \%(57)$ \\
No & $100 \%(7)$ & $71 \%(42)$ & $61 \%(42)$ & $65 \%(24)$ & $67 \%(115)$ \\
\hline
\end{tabular}

${ }^{a}$ AMS is based on ESQ score $\geq 0.7$.

${ }^{b} P<.044$.

adult single-use nasal cannula was placed on each subject. The subject was instructed to breathe normally through his/her nose. Subjects rested for approximately 10 minutes while $\mathrm{PetCO}_{2}$ values were recorded until they became stable (no variation $>2 \mathrm{~mm} \mathrm{Hg}$ over $30 \mathrm{sec}-$ onds). This resting period controlled for within subject variability of $\mathrm{PetCO}_{2}$ levels and allowed us to document the most valid, steady-state measurement. At the same time, a pulse oximeter was placed as a probe on the subject's finger to record an $\mathrm{Spo}_{2}(\%)$. Three measurements were taken, and we used the average value during the same steady-state period for analysis. Subjects were given a copy of the ESQ to take to their hotels, which they completed on day 2 of being at altitude. Research assistants then collected the completed ESQ from the respective hotels the following day.

\section{DATA ANALYSIS}

Multiple linear regression was used to analyze the effects of covariates on AMS. Univariate analysis included $t$ tests and Wilcoxon signed-rank tests. All analysis was performed in $\mathrm{R}$ version 2.5 . $^{5}$

\section{Results}

The mean amount of time that subjects spent at 3326 meters prior to being enrolled was 3.9 hours. A total of 246 subjects were enrolled. Because of the difficult logistics of tracking subjects the next day, 74 were lost to follow-up, giving a total of 172 subjects. Thirty-three percent of participants $(n=57)$ exhibited AMS by ESQ criteria on day 2 . The highest prevalence of AMS oc- curred in subjects with initial $\mathrm{PetCO}_{2}$ levels between 36 and $40 \mathrm{~mm} \mathrm{Hg}$ and $\mathrm{SaO}_{2}$ of $72 \%$ to $86 \%$, while the lowest prevalence of AMS occurred in those subjects with initial $\mathrm{PetCO}_{2}$ levels between 23.7 and $30 \mathrm{~mm} \mathrm{Hg}$ and $\mathrm{SaO}_{2}$ of $93 \%$ to $96 \%$, (Tables 2 and 3). No significant differences existed when examining $\mathrm{PetCO}_{2}$ and $\mathrm{SpO}_{2}$, and initial ESQ score between those subjects who did and did not complete the study. Mean $\mathrm{PetCO}_{2}$ was a significant predictor of an ESQ score consistent with AMS ( $P$ $<.044)$. For each $1 \mathrm{~mm} \mathrm{Hg}$ increase in mean $\mathrm{Petco}_{2}$, the ESQ score on day 2 increased by 0.025 . Each $1 \%$ increase in $\mathrm{SaO}_{2}$ decreased ESQ score by 0.018 , although this decrease was not statistically significant $(P=.19)$. Smoking, use of acetazolamide or coca, and age did not have independent effects on ESQ score.

With further analysis, $57 \%$ of the trekkers with initial pulse oximetry of $72 \%$ to $86 \%$ had AMS, and only $21 \%$ of those individuals with $\mathrm{SaO}_{2}$ values between $93 \%$ and $96 \%$ had AMS. If the $\mathrm{PetCO}_{2}$ data are divided into 4 groups encompassing an $\mathrm{Petco}_{2}$ of $<30,31-35,36-40$, and $>41 \mathrm{~mm} \mathrm{Hg}$, subjects within the $<30 \mathrm{~mm} \mathrm{Hg}$ group had the lowest incidence of AMS, and those subjects with an $\mathrm{PetCO}_{2}$ between $36-40 \mathrm{~mm} \mathrm{Hg}$ had the highest incidence of AMS.

\section{Discussion}

The results of this study show that subjects with the lowest $\mathrm{PetCO}_{2}$ values had the lowest incidence of AMS among tourists ascending rapidly to Cusco, Peru, at 3326 meters. Analysis of the $\mathrm{SpO}_{2}$ data showed a trend toward a negative correlation between $\mathrm{SpO}_{2}$ and AMS. Using $\mathrm{PetCO}_{2}$ as a reflection of alveolar ventilation upon ascent

Table 3. Initial $\mathrm{SaO}_{2}$ level and its correlation to Day 2 acute mountain sickness (AMS) ${ }^{a}$

\begin{tabular}{cccccccc}
\hline $\mathrm{SaO}_{2}$ range \% & $72-86.3$ & $86.4-88.2$ & $88.2-90.6$ & $90.6-91.7$ & $91.7-93.0$ & $93.1-96.0$ & Combined \\
\hline AMS & $\mathrm{n}=29$ & $\mathrm{n}=28$ & $\mathrm{n}=32$ & $\mathrm{n}=26$ & $\mathrm{n}=28$ & $\mathrm{n}=29$ & $\mathrm{n}=172$ \\
Yes & $59 \%(17)$ & $36 \%(10)$ & $25 \%(8)$ & $31 \%(8)$ & $29 \%(8)$ & $21 \%(6)^{b}$ & $33 \%(57)$ \\
No & $41 \%(12)$ & $64 \%(18)$ & $75 \%(24)$ & $69 \%(18)$ & $71 \%(20)$ & $79 \%(23)$ & $67 \%(115)$ \\
\hline
\end{tabular}

${ }^{a} \mathrm{SpO}_{2}$ ranges determined by approximation of equal group size.

${ }^{b} P<.19$. 
to this altitude, these findings suggest that those subjects with the greatest increase in alveolar ventilation on the first day at altitude will have the lowest incidence of AMS 24 hours later. Furthermore, this study is the first to investigate the incidence in Cusco, Peru, a popular tourist town from trekkers to the Andes.

Our results agree with previously published study by Bartsch et al, ${ }^{6}$ which documented that those subjects who had the lowest increase in alveolar ventilation on the first day at altitude had a higher prevalence of AMS. Hackett et al demonstrated in a study of 106 climbers on Mount McKinley that those subjects with the lowest $\mathrm{PetCO}_{2} \mathrm{~mm}$ $\mathrm{Hg}$ and the highest $\mathrm{SaO}_{2} \%$ on the first day at altitude have the lowest prevalence of $\mathrm{AMS}^{7}{ }^{7} \mathrm{Low} \mathrm{SaO}_{2}$ on arrival to altitude has also been a good predictor of an ESQ score consistent with AMS. ${ }^{8}$

This study was not designed to evaluate the relationship of ventilation, $\mathrm{PetCO}_{2}$, and cerebral blood flow (CBF) with AMS, and the logistics of such a field study precluded this possibility, which may have given us more insight into the mechanism of AMS. For years, there has been a controversy regarding the regulation of CBF and its relationship to the development of AMS. Cerebral autoregulation is the ability of the normal brain to respond to changing physiologic conditions, such as hypoxemia and hyper- and hypocapnia, to optimize oxygen delivery. Hackett et al found that symptoms of AMS correlated with the loss of CBF autoregulation and the development of cerebral edema and raised intracranial pressure. ${ }^{9}$ Subjects experience both hypoxemia and hypocapnia on arrival to high altitude, both of which have large effects on CBF, and it was difficult to determine whether ventilation or oxygenation have greater effects on $\mathrm{CBF} .{ }^{10,11}$ Unfortunately, our study does not elucidate these issues, but based on our analysis of how much each factor will increase or decrease the final ESQ score, initial $\mathrm{PetCO}_{2}$ explains more of the predictability of developing AMS than does $\mathrm{Spo}_{2}$. Each $1 \mathrm{~mm} \mathrm{Hg}$ increase in mean $\mathrm{PetCO}_{2}$ is estimated to increase ESQ score by $0.025(P=.044)$, and each $1 \%$ decrease in $\mathrm{Spo}_{2}$ is estimated to decrease ESQ score by $0.018(P=.19)$. Therefore, our data suggest that the initial ventilatory response has more of an impact on the future development of AMS than does oxygen saturation. $\mathrm{PetCO}_{2}$ is a more reliable reflection of alveolar ventilation, whereas $\mathrm{SpO}_{2}$ is related both to alveolar ventilation and alterations in gas exchange, which may occur on rapid ascent to high altitude.

Our results of approximately $33 \%$ of people $(n=57)$ having AMS by ESQ criteria are consistent with the study by Honigman and colleagues in Summit County, $\mathrm{CO}$, where $42 \%$ of participants experienced AMS at 3000 meters $(10,000 \mathrm{ft}) .{ }^{12}$ The high incidence of AMS seen at Cusco, a slightly higher altitude $(3326 \mathrm{~m})$, is likely related to the rapid ascent by airplane from Lima. Furthermore, many sojourners to high altitude use acetazolamide to prevent AMS. We found no significant effect of acetazolamide use on day 2 ESQ score, but our power to detect any difference was probably diminished due to the small sample of persons taking acetazolamide. A recent study evaluated mountain sickness knowledge among foreign travelers in Cuzco, Peru and found that only $9 \%$ of the subjects in this study knew about acetazolamide as prophylaxis for or treatment of AMS. ${ }^{13}$

Limitations of our study are those inherent in many similar field studies. Selection bias may have affected our results, as a portion of the 74 subjects lost to follow-up may have failed to complete the study due to AMS symptoms. However, the initial $\mathrm{PetCO}_{2}$, pulse oxygenation, and initial ESQ score are similar between subjects who dropped out and subjects who completed the study. The mean time for enrollment was close to 4 hours, but the ventilatory response to ascent should not vary appreciably between individuals within that time. A possible limitation is there is a delay between measurements of $\mathrm{ETCO}_{2}$ and AMS and the validity of inferring the ventilatory response at enrollment versus day 2 . However, the acute and ongoing ventilatory response and renal compensation occurring at high altitude are part of a very complex process called respiratory acclimatization. Although ventilation increases over time at altitude, inherent chemosensitivity and thus ventilatory responses to altitude change in parallel over time. ${ }^{14,15}$ In other words, the hypoxic ventilatory response in an individual measured at low altitude, if it is at the high end of responses compared to others, will continue to be higher than others during and after acclimatization and vice versa with low responders. Thus, we feel that our early measurements will not be physiologically different, and all would have changed in parallel. Thus, if ventilation has an influence on adaptation and maladaptation at altitude, the ESQ measurements will be valid, especially at 24 hours.

In conclusion, this study is the first analysis of AMS incidence among trekkers arriving in Cusco, Peru. It also provides further insight into AMS and its relationship to the individual variability of ventilatory response upon ascent to high altitude.

\section{Acknowledgment}

The authors greatly appreciate the hard work in the collection of data by Jillian H. Verby from the University of Nevada School of Medicine, Reno, NV, and David J. Price from New York Medical College, Valhalla, NY, as well as the statistical analysis performed by Peter Holck 
$\mathrm{PhD}$, MPH, Department of Public Health Sciences, John A. Burns School of Medicine University of Hawaii, Manoa. We would also like to thank Debra Ford of Respironics Novametrix for the generous donation of $\mathrm{ETCO}_{2}$ monitors for this project and Dr Humberto Guerra, MD, PhD, Professor de Medicina, Instituto de Medicina Tropical Alexander von Humboldt, Universidad Peruana Cayetano Heredia for his facilitation of this study.

\section{References}

1. Hackett PH, Roach RC. High-altitude illness. N Engl J Med. 2001;345:107-114.

2. Hackett PH, Rennie D. The incidence, importance, and prophylaxis of acute mountain sickness. Lancet. 1976; 7996:1149-1155.

3. Honigman B, Theis MK, Koziol-McLain J, et al. Acute mountain sickness in a general tourist population at moderate altitudes. Ann Intern Med. 1993;118:587-592.

4. Sampson JB, Cymerman A, Burse BL, et al. Procedures for the measurement of acute mountain sickness. Aviat Space Environ Med. 1983;54:1063-1073.

5. R Development Core Team, 2007. R Foundation for Statistical Computing, Vienna, Austria. ISBN 3-900051-07-0. Available at: http://www.R-project.org. Accessed May 25, 2010.

6. Bartsch P, Swenson ER, Paul A, et al. Hypoxic ventilatory response, ventilation, gas exchange, and fluid balance in acute mountain sickness. High Alt Med Biol. 2002;3:361-376.
7. Hackett PH, Roach RC, Schoene RB, et al. Abnormal control of ventilation in high-altitude pulmonary edema. J Appl Physiol. 1988;64:1268-1272.

8. Roach RC, Greene ER, Schoene RB, et al. Arterial oxygen saturation for prediction of acute mountain sickness. Aviat Space Environ Med. 1998;69:1182-1185.

9. Hackett PH, Yarnell PR, Hill R, et al. High-altitude cerebral edema evaluated with magnetic resonance imaging: clinical correlation and pathophysiology. JAMA. 1998;280: 1920-1925.

10. Jansen GFA, Krins A, Basnyat B. Cerebral vasomotor reactivity at high altitude in humans. J Appl Physiol. 1999; 86:681-686.

11. Baumgartner RW, Bartsch P, Maggiorini M, et al. Enhanced cerebral blood flow in acute mountain sickness. Aviat Space Environ Med. 1994;65:726-729.

12. Honigman B, Hultgren HN, Theis K, et al. High-altitude pulmonary edema at a ski resort. West J Med. 1996;164: 222-227.

13. Merrit AL, Camerlengo A, Meyer C, et al. Mountain sickness knowledge among foreign travelers in Cuzco, Peru. Wilderness Environ Med. 2007;18:26-29.

14. Schoene RB, Roach RC, Hackett PH, Sutton JR, Cymerman A, Houston CS. Operation Everest II: Ventilatory adaptation during gradual decompression to extreme altitude. Med Sci Sports Exerc. 1990;22:804-810.

15. Schoene RB, Lahiri S, Hackett PH, et al. The relationship of hypoxic ventilatory response to exercise performance on Mount Everest. J Appl Physiol. 1984;56: $1478-1483$. 